\title{
Metamorphic brine generation and the density of Ceres' mantle
}

\author{
MOHIT MELWANI DASWANI AND JULIE CASTILLO- \\ ROGEZ
}

Jet Propulsion Laboratory, California Institute of Technology

Presenting Author: daswani@jpl.nasa.gov

We investigate the thermal evolution of Ceres' mantle in order to interpret the density data inferred from the Dawn spacecraft. [1] derived an average mantle density of $\sim 2430 \mathrm{~kg} / \mathrm{m}^{3}$, but accounting for slight departure from hydrostatic equilibrium [2], [3] inferred a mantle density of $\sim 2800-2900 \mathrm{~kg} / \mathrm{m}^{3}$. Both values are lower than rock density inferred from theoretical modeling. This discrepancy is likely due to brine-filled porosity in the mantle [4]. We show that even for a cool internal thermal evolution, Ceres' rocky material releases water as a consequence of low-grade metamorphism. Metamorphism leads to the devolatilization of minerals, pore compaction, and densification of the interior, e.g., the reaction antigorite $\rightarrow$ olivine + talc + water proceeds from $\sim 670 \mathrm{~K}$ to $970 \mathrm{~K}$.

We applied the thermal evolution model from [5] on plausible compositional building blocks: CI chondrites, CM chondrites, and comets, with varying amounts of initial water, and assuming different vertical maximum porosities $\left(\Phi_{\max }\right)$, using Rcrust [6]. Figure 1 shows selected results for a CM chondrite Ceres. Fig. 1a) shows the mean density at selected points in time for various amounts of initial water, and $\Phi_{\max }$ of vertical layers from the surface to the interior. Allowable densities $\left(2400-2900 \mathrm{~kg} / \mathrm{m}^{3}\right.$ ) are outlined in black; a major fluid releasing event is outlined in green at 2 Gyr. Fig. $1 b)$ shows solvents $\left(\mathrm{CO}_{2}-\mathrm{CH}_{4}-\mathrm{H}_{2} \mathrm{O}\right)$ released as a function of PT; dashed black line and solid black line are the pressure-temperature profiles at $100 \mathrm{Myr}$ and at present, respectively. Dashed orange line is the isobaric slice shown in 1c). Fig. 1c) shows mineral phases along the $50 \mathrm{MPa}$ isobaric slice as a function of temperature.

[1] Ermakov et al. (2017). J. Geophys. Res. Planets 122, 2267-2293. [2] Park et al. (2016). Nature 537, 515-517. [3] Mao \& McKinnon (2018). Icarus 299, 430-442. [4] Raymond et al. (2020). Nature Astronomy 4, 741-747. [5] Castillo-Rogez \& McCord (2010). Icarus 205, 443-459. [6] Mayne et al. (2016). J. Metamorph. Geol. 34, 663-682.

Part of this work was carried out at the Jet Propulsion Laboratory, California Institute of Technology, under contract to NASA.

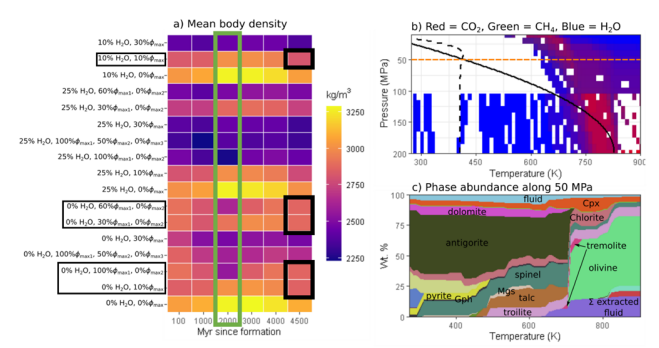

